\title{
DYNAMICS OF VEGETATION COVERAGE AND RESPONSE TO CLIMATE CHANGE IN CHINA-SOUTH ASIA-SOUTHEAST ASIA DURING 1982-2013
}

\author{
WEI, Z. F. ${ }^{1,2}-$ HUANG, Q. Y. ${ }^{2 *}$ ZHANG, R. ${ }^{3,4 *}$ \\ ${ }^{1}$ Business School, Sun Yat-Sen University, Guangzhou 510275, China \\ ${ }^{2}$ Guangxi University of Finance and Economics, NanNing 530003, China \\ ${ }^{3}$ Institute of Remote Sensing and Digital Earth, Chinese Academy of Sciences \\ Beijing 100101, China \\ ${ }^{4}$ University of Chinese Academy of Sciences, Beijing 100049, China \\ *Corresponding authors \\ e-mail:weizhenfeng112@163.com; ruizh581@163.com \\ (Received $16^{\text {th }}$ Oct 2018; accepted $16^{\text {th }}$ Jan 2019)
}

\begin{abstract}
The NASA global inventory modeling and mapping studies released one year and a half month maximum synthetic of global dat, based on which the authors analyzed data originated from the Chinese meteorological data sharing service science and data pertaining to northwest air temperature and precipitation, climate, month and year value data sets, etc throughout the period of 1982 to 2013. The Normalized Difference Vegetation Index (NDVI) was analyzed in terms of vegetation spatial analysis, using linear regression analysis, standard deviation, the Hurst index, and the partial correlation analysis methods. The results showed that from 1982 to 2013, the overall NDVI in China, South Asia, and Southeast Asia had an increasing trend. During the 1990s, the vegetation volatility was higher in China, South Asia, and Southeast Asia. Additionally, in the three areas, the NDVI change increased dramatically after 2008, but subsequently decreased in 2010. From 1980 to 2013, the ecological environment of the eastern part of China, the northeast and the south, East Asia, Southeast Asia, India, Thailand, Bangladesh, and the eastern part of Pakistan are generally good. In Western and Northwest China and in other Southeast Asian countries, in South Pakistan, the South and back, the eastern, southern and southwestern parts, the state of the ecological environment are generally poor. From 1998 to 2005, in China, Southeast Asia, and South Asia, the NDVI is reduced. From 2006 to 2013, in China, Southeast Asia, South Asia, the NDVI increased significantly.
\end{abstract}

Keywords: vegetation cover change, climate, China-South Asia-Southeast Asia, spatiotemporal response

\section{Introduction}

Vegetation is connected to the atmosphere, water, and soil, comprising the core of the land surface in the earth's ecosystem. Since photosyntheses is related to the degree of vegetation coverage, changes in vegetation coverage exert a significant goal impact, as they influence the properties of the land surface, soil and water conservation, climate regulation, and overall stability of the ecosystem (Meyer et al., 1992; Sun et al., 1998). 
Within the interaction between the earth spheres, the hydrological processes and the soilvegetation-atmosphere interactions and on global and regional climate and ecosystem of their feedback is the most basic frontier issue (Cao et al., 2011; Chang et al., 2011). Therefore, climate and vegetation share an inseparable relation, manifested mainly in two aspects: vegetation adaptability to climate and vegetation feedback effect on climate (Fung et al., 2000; Chen et al., 2015). Changes in vegetation influence the properties of soil surface such as moisture, which in turn will affect regional climate (Justice et al., 1986; Zhang et al., 2003). On the other hand, climate changes affect vegetation's growth; thus, the climate is the main factor influencing the distribution of the biological community, and its changes alter the structure of vegetation communities, composition, and biomass, thus shaping the forest ecological system and simultaneously decreasing biological diversity (Zhang et al., 2001; Cui et al., 2009). The Normalized Difference Vegetation Index (NDVI) characterizes surface vegetation and is sensitive to measure vegetations' growth parameters, thus comprising an effective index for quantitative characterization of vegetation growth (Yang et al., 2004; Yaşar et al., 2018). As such, the NDVI has been widely used in several areas such as agriculture, ecology, and environment. Recently, the association between NDVI and climate response has been studied by researchers of different areas (Zhang et al., 2007; Mr et al., 2017).

President Xi Jinping brought up the "One Belt And One Road" to promote close cooperation among different countries, including hazard-prone areas, such as China, South Asia, and Southeast Asia where natural disasters occur most frequently. Investigating the ecological environment of these countries may improve the prevention of regional disasters and the capacity to mitigate their effects. Additionally, it may improve the accuracy of climate change research in other areas, thus promoting the "One Belt And One Road" for an improved cooperation between countries (Wagner et al., 2014; Lu et al., 2016).

\section{Materials and Methods}

\section{Study Area}

The geographical scope of this research (Figure 1), followed the "One Belt And One Road" strategy, including China's south and southeast bordering countries, as follows: South Asia, including Afghanistan, Bangladesh, Bhutan, India, Nepal, and Pakistan; and Southeast Asia area including Cambodia, Laos, Myanmar, Thailand, and Vietnam (Wang et al., 2008).

\section{Data sources}

The GIMMS NDVI3g dataset was downloaded from the NOAA-Advanced Very High Resolution Radiometer (AVHRR) for the period from 1982 to 2013. GIMMS NDVI3g (http:// data.cma.cn/) has a spatial resolution of $1 / 12^{\circ}$ and a temporal resolution of 15 days (Fensholt and Proud, 2012; Guay et al., 2014). The GIMMS NDVI3g dataset has been optimized to minimize the effects of the differences in sensor design between the 
AVHRR/2 and AVHRR/3 instruments as well as volcanic eruptions (Pinzon and Tucker, 2014; Liu et al., 2015a, b). To further eliminate the interference of factors such as atmosphere, clouds, and angle of the sun (Hou, 2001), the maximum synthesis MVC (maximum value composites) is used to obtain the monthly and annual NDVI values. The monthly NDVI is calculated according to the following formula:

$$
M N D V I_{i}=\operatorname{Max}\left(N D V I_{1}, N D V I_{2}\right)
$$

In the formula: NDVI value of month $\mathrm{i}$; $i$ is the month number $(i=1,2,3 \ldots \ldots 12)$, denotes the NDVI value of the first half month and the second half month, respectively. Using the same MVC method to obtain the maximum monthly NDVI as the annual NDVI value. The formula is

$$
Y_{N D V I}=\operatorname{Max}\left(M N D V I_{1}, M N D V I_{2} \cdots, M N D V I_{12}\right)
$$

In the formula: $\mathrm{YNDVI}_{\mathrm{N}-\text {-annual }} \mathrm{NDVI}$ value; $\mathrm{MNDVI}_{1}, \mathrm{MNDVI}_{2} \ldots, \mathrm{MNDVI}_{12}$-Monthly NDVI values for January-December.

The temperature and precipitation data in the study area are mainly from the website: (http://www.cru.uea.ac.uk/) A gridded time-series dataset. This version, released 18 November 2018, covers the period 1901-2017. Coverage: All land areas (excluding Antarctica) at $0.5^{\circ}$ resolution.

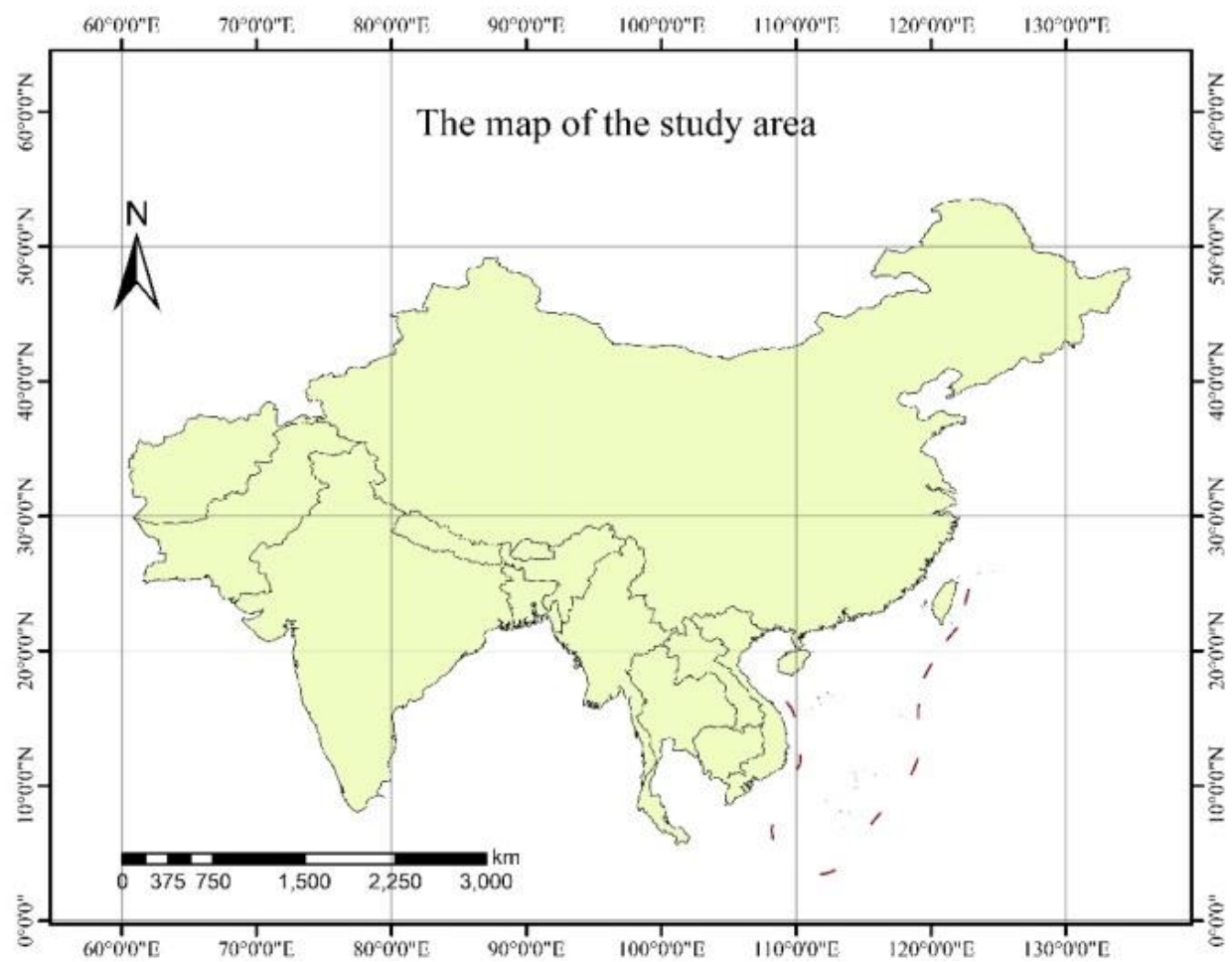

Figure 1. Location of the study area 


\section{Research methods}

Linear regression analysis was performed for vegetation, precipitation, and air temperature, along the factor time (Liu et al., 2015). That is, the linear regression coefficient a of vegetation NDVI and climate factor y over time $t$, as shown in formula (3).

$$
y=a t+b, \quad t=1,2, \cdots, n(n \leq 25)
$$

Sen+Mann-Kendall: The trends of changes in the spatial characteristics of vegetation were analyzed using the Sen method and tested using the Mann-Kendall method. These methods can avoid loss of data, outliers' interference, and influence of the data distribution patterns on the analysis results (Liu et al., 2013). The Sen trend was calculated using data pertaining to the NDVI from 1982 to 2013, according to the following formula:

$$
\rho=\operatorname{median} \frac{\left(x_{j}-x_{i}\right)}{j-i}, \quad 1<\mathrm{i}<\mathrm{j}<\mathrm{n}
$$

where $\mathrm{x}_{j}, \mathrm{x}_{i}$-- time series data. $\rho<0$ shows a downward trend, whereas the reverse shows an upward trend. The Mann-Kendall method was used to test whether the trend was significant.

The Mann-Kendall test (MK test) is one of the most commonly used time series trend test methods and does not require the sample to follow a certain distribution and is suitable for non-normally distributed data. The method is based in the following formulas:

$$
\begin{gathered}
Q=\sum_{i=1}^{n-1} \sum_{j=i+1}^{n} \operatorname{sign}\left(x_{j}-x_{i}\right) \\
\operatorname{sign}(s)= \begin{cases}1 & (s>0) \\
0 & (s=0) \\
-1 & (s<0)\end{cases} \\
z= \begin{cases}\frac{Q-1}{\sqrt{V(Q)}} & (Q>0) \\
0 & (Q=0) \\
\frac{Q+1}{\sqrt{V(Q)}} & (Q<0)\end{cases}
\end{gathered}
$$


where: Q - test statistic; Z - normalized test statistic; $\mathrm{x}_{j}, \mathrm{x}_{i}$ - time series data; $\mathrm{n}$ - sample number; when $\mathrm{n} \geq 8$, $\mathrm{Q}$ is approximately positive distribution, the mean and variance are calculated as follows:

$$
\begin{gathered}
E(Q)=0 \\
V(Q)=\frac{n(n-1)(2 n-5)}{18}
\end{gathered}
$$

After standardization, $Z$ is the standard distribution, if $|z|>z_{1-a / 2}$, then it is significant trend change. $z_{1-a / 2}$ is the corresponding value for the standard positive distribution table at the confidence level a. In this paper, the confidence level is 0.05 , and the degree of freedom is $25-2=23$.

Standard Deviation Analysis: The standard deviation indicates the distance of the data variable from the mean, which reflects the discrete degree of a data set. The larger the value is, the farther the NDVI distance is, the greater the vegetation change (Liu et al., 2015). The formula as follow:

$$
S_{i}=\sqrt{\frac{1}{n} \sum_{i=1}^{n}(N D V I-\overline{N D V I})^{2}}
$$

According to the standard deviation value of 5 grades of vegetation change intensity: High $\left(\mathrm{S}_{\mathrm{i}} \leq 2.00\right)$, high $\left(2.00 \leq \mathrm{S}_{\mathrm{i}}<4.00\right)$, medium $\left(4.00 \leq \mathrm{S}_{\mathrm{i}}<6.00\right)$, lower $\left(6.00 \leq \mathrm{S}_{\mathrm{i}}<8.00\right)$, and low $\left(8.00 \leq \mathrm{S}_{\mathrm{i}}<10.00\right)$. The spatial characteristics of vegetation cover fluctuation in the region for many years.

Hurst index: Time series with long-term dependence in nature are ubiquitous. Hurst index is one of the effective methods to quantitatively describe the long-term dependency of time series information. The calculation principle is as follows:

For any positive integer $\tau \geq 1$, define the mean sequence $\{\xi(t)\}$

$$
\langle\xi\rangle_{\tau}=\frac{1}{\tau} \sum_{t=1}^{\tau} \xi(t) \quad \tau=1,2, \cdots, N
$$

Accumulation deviation:

$$
X(t, \tau)=\sum_{u}^{t}\left(\xi(t)-\langle\xi\rangle_{\tau}\right), \quad 1 \leq t \leq \tau
$$


Very poor:

$$
R(\tau)=\max _{1 \leq t \leq \tau} X(t, \tau)-\min _{1 \leq t \leq \tau} X(t, \tau), \quad \tau=1,2, \cdots
$$

Standard deviation:

$$
S(\tau)=\left[\frac{1}{\tau} \sum_{t=1}^{\tau}\left(\xi(t)-\langle\xi\rangle_{\tau}\right)^{2}\right]^{\frac{1}{2}}, \quad \tau=1,2, \cdots N
$$

Consider the ratio $\mathrm{R}(\tau) / \mathrm{S}(\tau)$. If there is $\mathrm{R} / \mathrm{S} \propto \tau \mathrm{H}$, then the time series $\{\xi(\mathrm{t})\}$ exist Hurst phenomenon, $\mathrm{H}$ called Hurst index. In the double logarithmic coordinate system $(\ln \tau, \ln R / S)$ with the least squares fitting.

1) If $0.5<\mathrm{H}<1$, it indicates that time series of NDVI as long-term positive correlation.

2) If $\mathrm{H}=0.5$, the time series of NDVI are independent random sequences.

3) If $0<\mathrm{H}<0.5$, the time series data of NDVI have anti-persistence, and the sequence has abrupt jump characteristics. H value closer to 0 , the stronger the anti-persistence; closer to 1 , the more positive continuity.

\section{Results}

\section{Interannual change of NDVI in the area}

Using the values of NDVI corresponding to the period between 1982 and 2013, analysis of regional mean annual variation characteristics, provided the annual NDVI variation characteristics graph below (Figure 2):

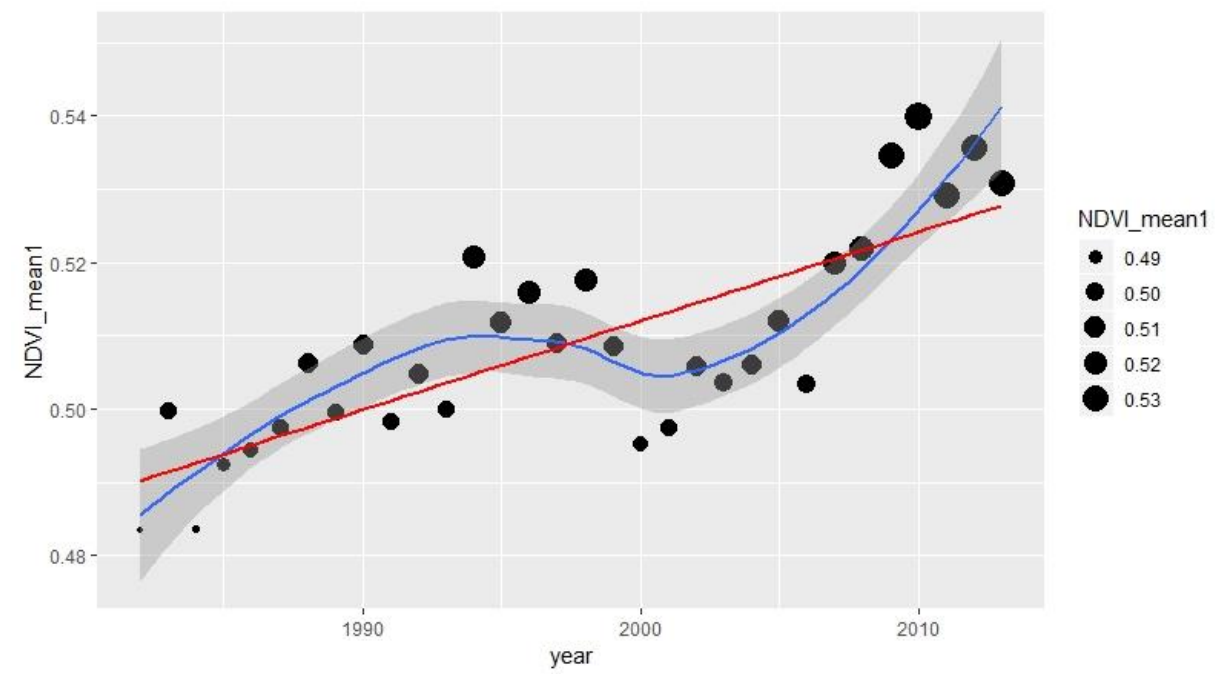

Figure 2. Annual variation characteristics of NDVI from 1982 to 2013 in South Asia 
As can be seen from Figure 2, Between 1982 and 2013, the interannual variation of the average value of NDVI in South Asia shows an increasing trend. In the late 1990s, there was a small fluctuations, that is a downward trend. High values appeared in 1994 and low values appeared in 2000. After 2000, there was a tendency to resume growth.

From Figure 3, the interannual variation of the NDVI regional average in Southeast Asia is the same as that in South Asia. Among them, the growth trend appeared in the 1980s. Also fluctuating in the 1990s, during which low values occurred in 1993 and high values appeared in 1994. After 2000, there is a growing trend.

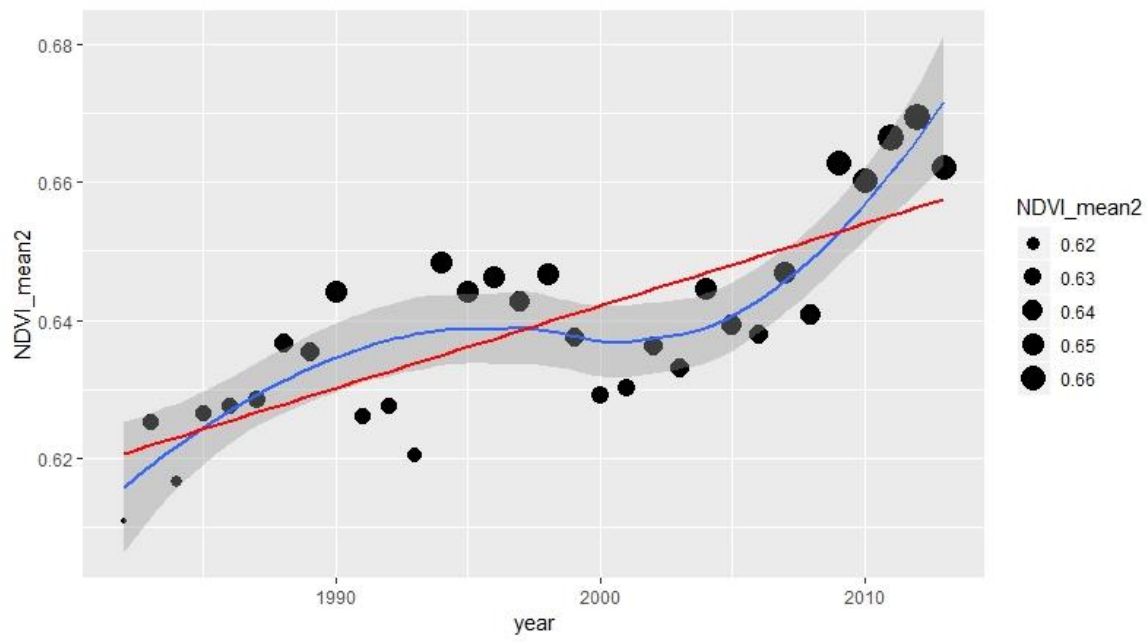

Figure 3. Annual variation characteristics of NDVI from 1982 to 2013 in Southeast Asia

From Figure 4, between 1982 and 2013, the interannual variability of China's NDVI regional average is the same as that of South Asia and Southeast Asia. It is a growth trend in the 1980s, and it has a downward trend in the 1990s, and then it has become a growth trend. The magnitude of the change is relatively large compared to other regions.

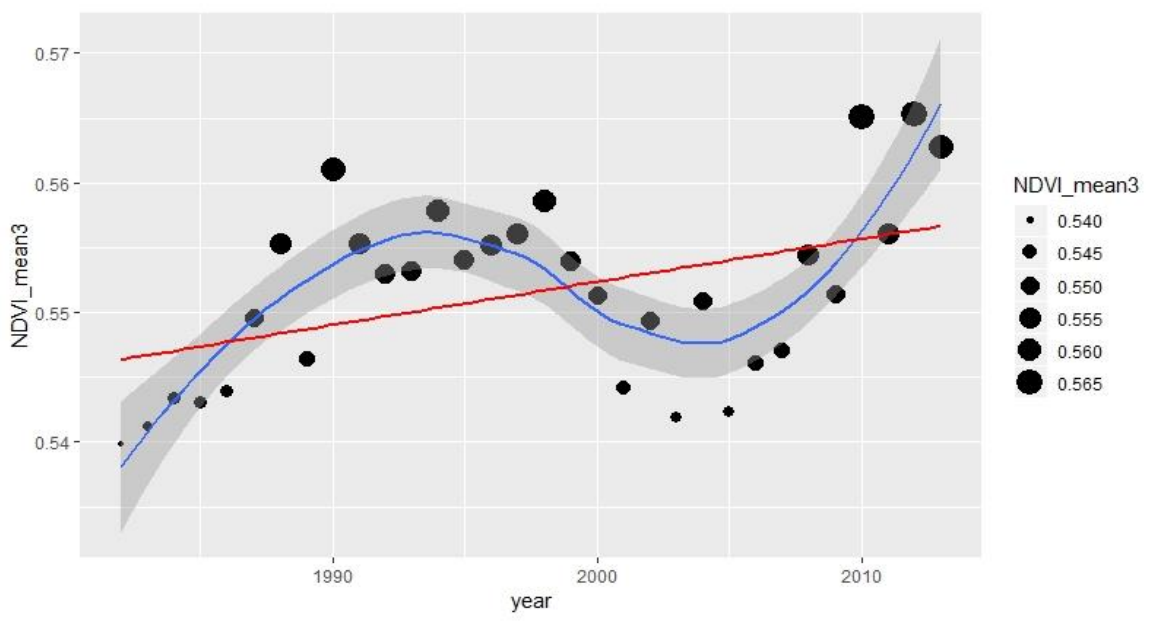

Figure 4. Interannual variability of NDVI in China from 1982 to 2013 (Remark: Annual average of the statistical study area) 
Summary, the interannual variability of NDVI in these three regions is similar, showing a growing trend in the 1980s, a downward trend in the 1990s, and a growth trend in the 2000s. In the 1990s, the interannual variation of China's NDVI regional values fluctuated significantly. These are all in sync with regional social development. In the 1990s, all regions were developing, pursuing economic development and neglecting ecological environmental protection. After the 2000 s, everyone realized the importance of the ecological environment, so that they pursued economic development while also paying attention to the protection of the ecological environment. Therefore, the regional average NDVI has shown an increasing trend since the 2000s. Due to the rapid development of China, the damage to the environment was so great that there was a large fluctuation in the 1990s.

\section{Spatial distribution of SEN trend in the study area}

In the present study, the SEN method was used to analyze the spatial trends of vegetation characteristics and to test them using the Mann-Kendall method, thus determining the trend of NDVI in China, South Asia, and Southeast Asia from 1982 to 2013 (Figure 5).

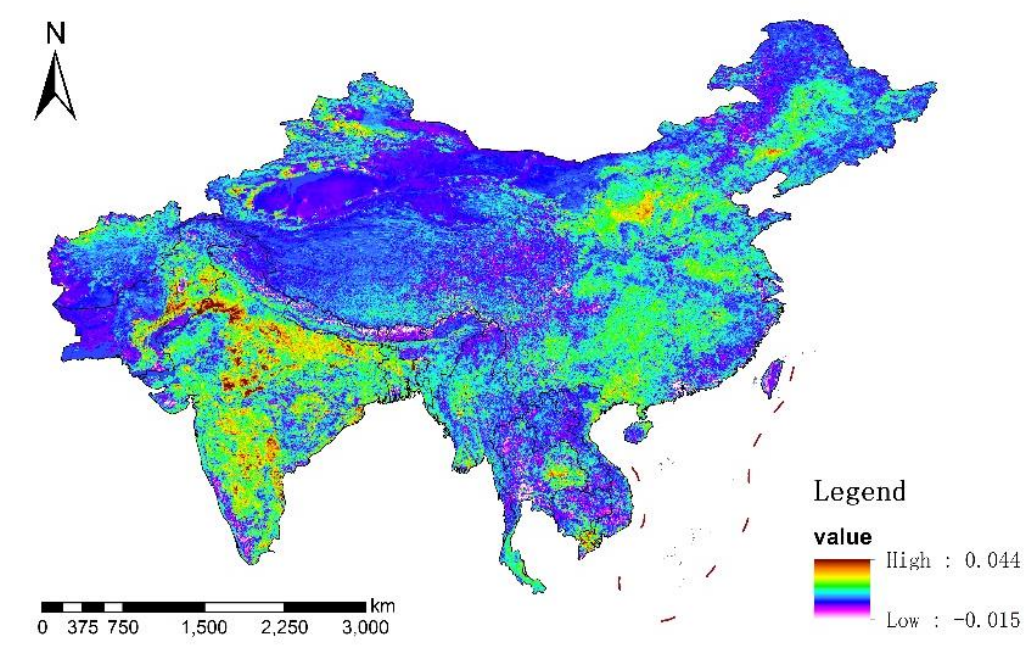

Figure 5. Spatial distribution of SEN trend in the study area, 1982-2013

As shown in the above picture, in China, Southeast Asian countries, and South Asian countries, most positive SEN values, indicating a good ecology. The SEN is high in the eastern, central and northeastern China and low in the west and northwest china. Most SEN values are low for Southeast Asia, Vietnam, Cambodia, and Laos and higher in eastern and southern Thailand and central Myanmar. In the South Asian countries of Bangladesh, India, eastern Pakistan, southeast and northeast, northern Afghanistan, eastern Nepal, and southern Bhutan, SEN values are high, with 0.044 being the the highest value observed. 


\section{Spatial distribution characteristics in different periods}

The spatial trend of the NDVI in the four periods of 1982-1989, 1990-1997, 1998-2005, and 2006-2013 was analyzed using Hurst exponent and partial correlation analysis (Figure 6).
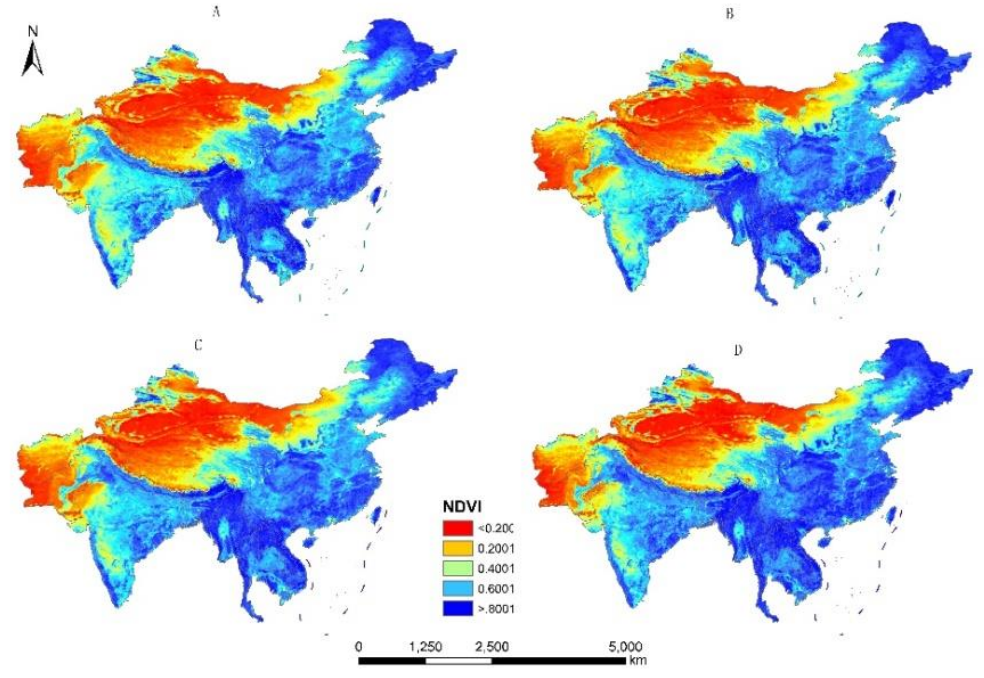

Figure 6. Multi-year mean spatial distribution of the study area

The NDVI of the eastern, southeastern and northeastern parts of China was above 0.6, whereas it was lower than 0.2 in the northwestern part of China, and higher than 0.6 in some parts of northern Xinjiang. In the Southeast Asian countries of Vietnam, Cambodia, Laos, Thailand, and Myanmar, as well as in South Asia; Nepal; Bangladesh; Bhutan; and central, eastern, and northern parts of India, the NDVI was higher than 0.6. With in South Afghanistan and Pakistan it was below 0.2, whereas in much of Afghanistan it was below 0.6 .

In terms of spatial and temporal distribution, the NDVI decreased from 0.6001 to 0.8 , especially in China and India. In Southeast Asia, Bhutan and Bhutan Bengal it remained unchanged. In the four studied time periods, the largest NDVI changes occurred from 2006 to 2013.

Overall, the NDVI values were mainly distributed over Southeast Asia, eastern and northeastern China, with the lowest values concentrated mainly in western South Asia and the Qinghai-Tibet Plateau of China. The spatial distribution of vegetation cover was related to its topographic distribution with a relatively high NDVI near the coast.

\section{Spatial variability of vegetation cover change in the study area}

The variation of vegetation coverage in the study area was calculated through the coefficient of variation, whereupon the interannual variability of vegetation coverage increased with an increasing coefficient of variation. For example, in the west and northwest of the study area, the topography is relatively high, as is the coefficient of 
variation. In the Indian Peninsula, Southeast Asia and The coefficient of variation in China's coastal areas is low. The spatial distribution of NDVI is also similar to that of the study area. The interannual variation range of NDVI is low, whereas its overall range is relatively high. Overall, the interannual variability of vegetation cover over the past 32 years was relatively low, which indicated a stable ecological change of vegetation within the study area (Figure 7).

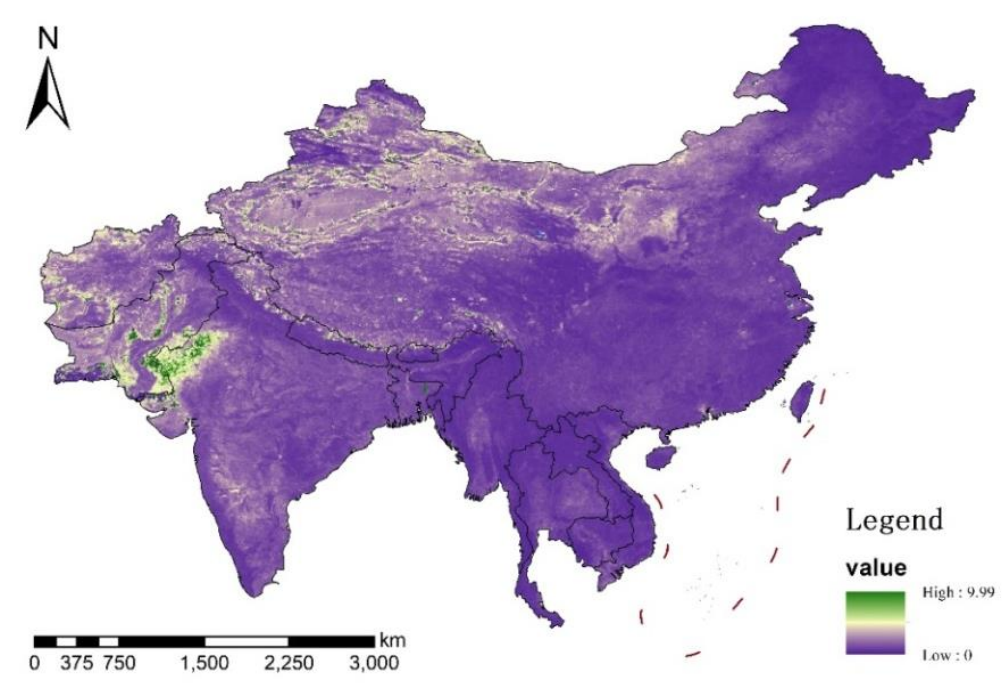

Figure 7. 1982-2013 Spatial distribution of NDVI variation coefficient in the study area

\section{HURST index space characteristics of sustainable change}

The spatial change characteristics of vegetation coverage in the study area from 1982 to 2013 were calculated on the basis of the HURST index (Figure 8).

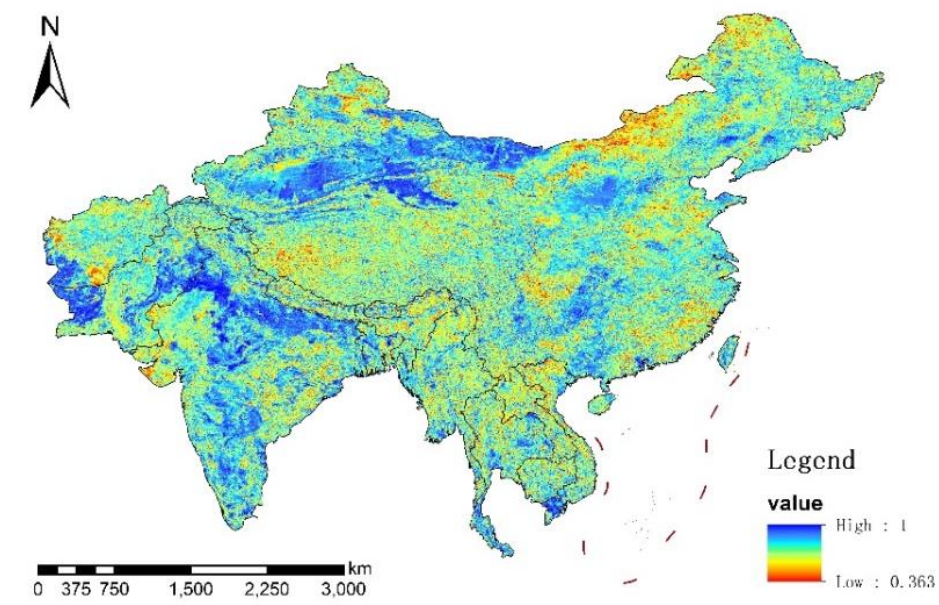

Figure 8. 1982-2013 The HURST spatial distribution in the study area 
Regarding the spatial distribution of the HURST index, most values within the study area ranged between 0.3 and 1 , with most areas exhibiting a value higher than 0.5 . Most regions corresponded to northwestern China and parts of the Indian Peninsula in South Asia. Overall, the main trend of vegetation cover change in this region was a normal trend, showing that the ecological vegetation coverage in the study area improved over 32 years, further indicating an improvement of the region's ecological environment.

\section{Spatial distribution characteristics of vegetation cover change and climate response}

In the present study, the correlation between vegetation cover and precipitation within the study area was analyzed, and we concluded (Figure 9) that in most areas the vegetation cover was obviously correlated with precipitation, especially in South Asia and Inner Mongolia, in northern China. Only a few regions exhibited negative correlations, which were not obvious. It may therefore be concluded that the changes in vegetation cover within the research area and over the past 32 years are strongly influenced by precipitation.

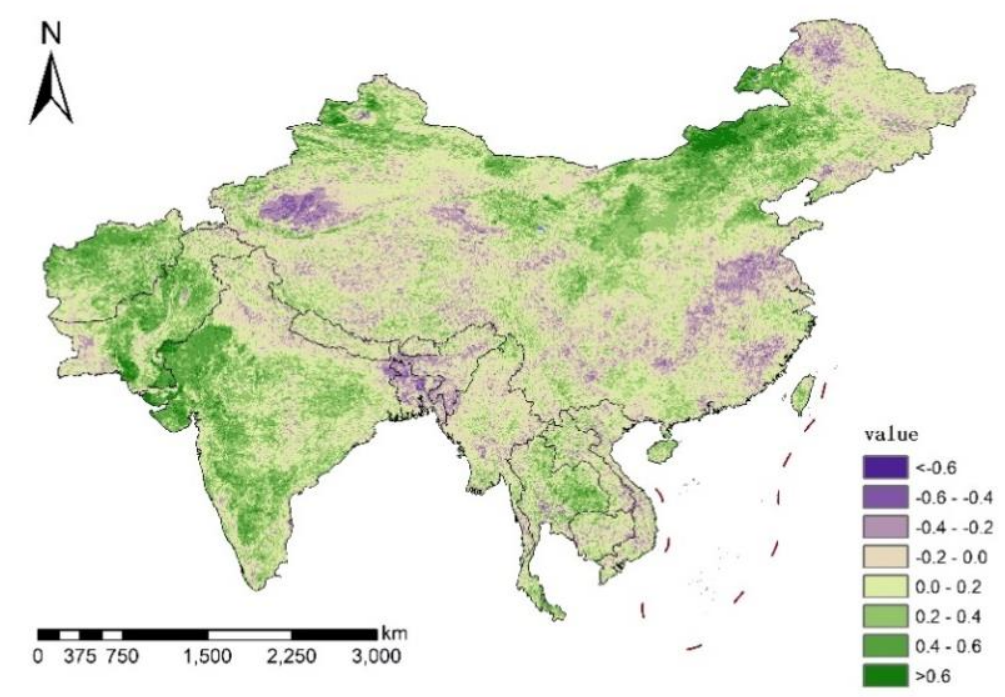

Figure 9. 1982-2013 Partial correlation NDVI and precipitation apace distribution in study area

Moreover, as can be observed from Figure 10, in most areas, the response in vegetation cover changes has a positive correlation with temperature, with only a few areas showing a negative correlation, thus showing vegetation cover changes are affected by temperature.

In summary, the influence of temperature and precipitation is positively correlated with the changes of the vegetation cover, and the area of NDVI and precipitation correlation coefficient in the study area is northeast China, eastern Thailand and Central and northwest of South Asia. The correlation coefficient between NDVI and temperature is in the central, eastern, and southern parts of China; southern Vietnam; eastern Thailand; 
central Burma; and Central Asia. Therefore, it is concluded that vegetation growth is closely related to precipitation and temperature.

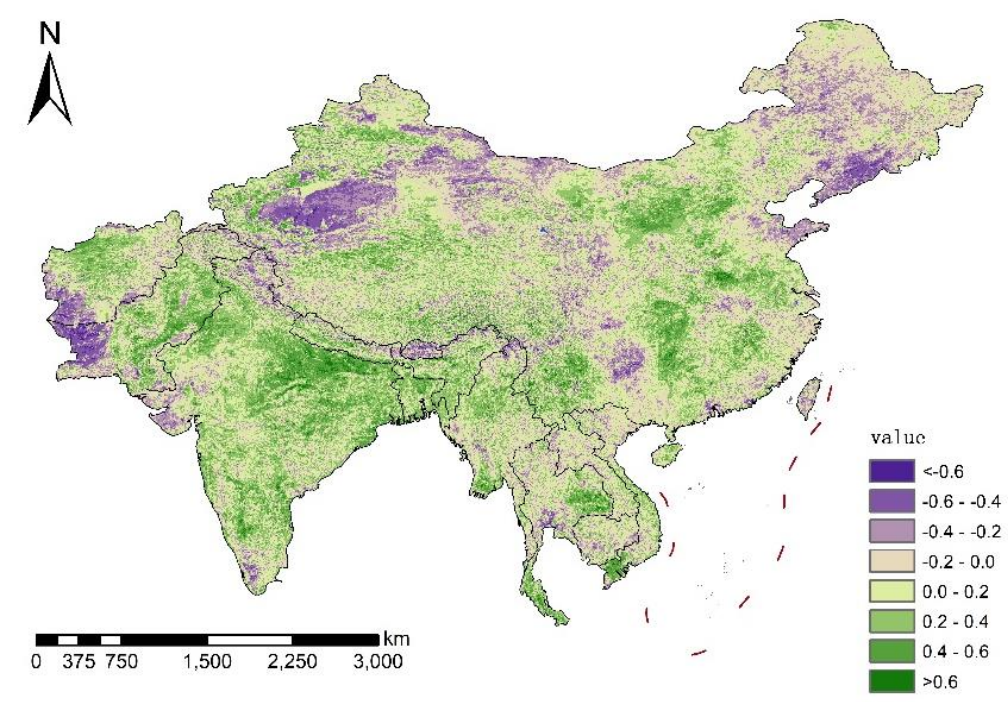

Figure 10. 1982-2013 Partial correlation NDVI and temperature apace distribution in study area

\section{Discussion}

The present study monitored vegetation growth in three regions of China, South Asia, and Southeast Asia by analyzing data pertaining to NDVI time series (Liu et al., 2015a). Additionally, the growth status of agricultural vegetation within the study area was monitored (Zhang et al., 2013b). The results show that large-scale agricultural vegetation monitoring can be carried out by satellite remote sensing. However, due to the constraints of NDVI data resolution and the complexity of vegetation changes, several problems remain to be clarified (Zhang et al., 2013a):

1) The GIMMS-NDVI data resolution is $8 \mathrm{~km} \times 8 \mathrm{~km}$, and the relationship between the agricultural vegetation-climate in China-South Asia and South-East Asia cannot be fully reflected, and the study area should be more refined by using more highresolution NDVI datasets and data from different sources.

2) Factors affecting agricultural vegetation cover include, in addition to rainfall, temperature and topography, hydrology, and soil and insect infestation, which should be taken into account in subsequent studies.

3) This paper studies changes in climate and agricultural vegetation coverage, without considering the influence of human activities. Human activities include the expansion of urbanization, agricultural modernization management, and ecological environment construction.

4) By studying the NDVI vegetation coverage, this paper studies the agricultural vegetation coverage in the study area, and does not consider the influence of other kinds of vegetation coverage on the study of agricultural vegetation coverage. 


\section{Conclusions}

On the basis of the analysis of the temporal and spatial NDVI trends in different climatic regions and some countries in China, South Asia, and Southeast Asia from 1982 to 2013, the following conclusions are taken:

1) Between 1982 and 2013, the average annual NDVI trends in China, South Asia, and Southeast Asia increased. Although the increase was relatively small in South Asia, it was higher in Southeast Asia and China. After the 1990s, the NDVI vegetation changes in China, South Asia, and Southeast Asia were fluctuant. After 2008, the NDVI of the three regions all increased significantly, subsequently declining by 2010 .

2) The ecological environment of eastern, northeastern, and southern China; eastern Thailand; South Asia; India; Bangladesh; and eastern Pakistan was generally good in 1980 to 2013. The western and northwestern parts of the country, other countries in Southeast Asia, western Pakistan, south, back, eastern Afghanistan, south and southwest of Pakistan are generally poor in terms of ecological environment.

3) From 1998 to 2005, NDVI vegetation indices in China, Southeast Asia, and South Asia decreased, subsequently increasing over 2006 and 2013.

4) During nearly 32 years of study within the area, the interannual vegetation amplitude is small, with a relatively stable vegetation coverage, where only a few areas larger fluctuation.

5) According to the HURST index calculation, most the study area in most of the vegetation coverage were positively state change trend, a handful of areas reverse the trend.

Comprehensive above, study nearly 32 years of vegetation changes gradually in the study area, the ecological environment is improved, a further sign of the government and people pay more and more attention to ecological environment construction, so that the ecological vegetation restoration is more obvious.

Funding. This research was funded by "Management Science and Engineering" construction funding for key disciplines in Guangxi, Karst land use change ecological effect side evaluation ecological security research (GK2015010), and the perspective of rural revitalization of natural resources accounting and ecological security research in Northwest Guangxi (2018QNB13).

Conflict of Interests. The authors declare that they have no conflict of interests.

\section{REFERENCES}

[1] Cao, S. X., Chen, L., Shankman, D., Wang, C. M., Wang, X. B., Zhang, H. (2011): Excessive reliance on afforestation in China's arid and semi-arid regions: lessons in ecological restoration. - Earth-Sci Rev 104: 240-245.

[2] Chang, R. Y., Fu, B. J., Liu, G. H., Liu, S. G. (2011): Soil carbon sequestration potential for Bgrain for green project in loess Plateau, China. - Environ Manag 48(6): 1158-1172.

[3] Chen, Y. P., Wang, K. B., Lin, Y. S., Shi, W. Y., Sony, Y., He, X. H. (2015): Balancing green and grain trade. - Nat Geosci 8: 739-741. 
[4] Cui, L. L., Shi, J., Yang, Y. M. (2009): Characteristics of NDVI response to climate and precipitation in eastern China. - Journal of Geographical Sciences 24(7): 850-860.

[5] Fung, T., Siu, W. (2000): Environmental quality and its changes, an analysis using NDVI. - International Journal of Remote Sensing 21(5): 1011-1021.

[6] Guay, K. C., Beck, P., Berner, L. T., Goetz, S. J., Baccini, A., Buermann, W. (2014): Vegetation productivity patterns at high northern latitudes: a multisensor satellite data assessment. - Glob Chang Biol 20: 3147-3158.

[7] John, R., Chen, J. Q., Ou-Yang, Z. T., Xiao, J. F., Becker, R., Samanta, A., Ganguly, S., Yuan, W. P., Batkhishig, O. (2013): Vegetation response to extreme climate events on the Mongolian Plateau from 2000 to 2010. - Environ Res Lett 8 (UNSP 0350333).

[8] Justice, C. O. (1986): Monitoring the grassland of semi-arid Africa using NOAA-AVHRR data. - International Journal of Remote Sensing 7(7): 1381-1622.

[9] Li, Z., Zheng, F. L., Liu, W. Z., Flanagan, D. C. (2010): Spatial distribution and temporal trends of extreme temperature and precipitation events on the loess Plateau of China during 1961-2007. - Quatern Int 226: 92-100.

[10] Liao, H., Chang, W. Y. (2014): Integrated assessment of air quality and climate change for policy-making: highlights of IPCC AR5 and research challenges. - Natl Sci Rev 1: 176179.

[11] Liu, Y., Lei, H. (2015): Responses of natural vegetation dynamics to climate drivers in China from 1982 to 2011. - Remote Sens-Basel 7(8): 10243-10268.

[12] Liu, G., Liu, H. Y., Yin, Y. (2013): Global patterns of NDVI-indicated vegetation extremes and their sensitivity to climate extremes. - Environ Res Lett 8(0250092).

[13] Liu, X. F., Zhu, X. F., Pan, Y. Z., Zhao, A. Z., Li, Y. Z. (2015): Spatiotemporal changes of cold surges in Inner Mongolia between 1960 and 2012. - J Geogr Sci 25: 259-273.

[14] Liu, Y. X., Liu, X. F., Hu, Y. N., Li, S. S., Peng, J.,Wang, Y. L. (2015): Analyzing nonlinear variations in terrestrial vegetation in China during 1982-2012. - Environ Monit Assess 187(72211)

[15] Lu, P., Yu, Q., He, Q. T. (2016): Responses of plant phenology to climatic change. - Acta Ecologica Sinica 26(3): 923-929.

[16] Meyer, W. B., Turner, B. L. (1992): Human population growth and global land-use/cover change. - Annual Review of Ecology and Systematics 23(1): 39-61.

[17] Mr, Z., Zhang, Z. H., Meng, Y. Z. (2017): The OSGi framework under heterogeneous remote sensing based on LDAP service invocation mechanism research. - Computer application research 01: 1-6.

[18] Sun, H. Y., Wang, C. Y., Niu, Z., Bu, A., Li, B. (1998): Characteristics of surface vegetation cover change and its climatic factors in China: based on NOAA time series data analysis. - Journal of Remote Sensing 03: 204-210.

[19] Wagner, M. J., Bladon, K. D., Silins, U., Williams, C. H., Martens, A. M., Boon, S., MacDonald, R. J., Stone, M., Emelko, M. B., Anderson, A. (2014): Catchment-scale stream temperature response to land disturbance by wildfire governed by surface-subsurface energy exchange and atmospheric controls. - Journal of Hydrology 517: 328-338.

[20] Wang, S., Zhang, Q., Wei, G. (2005): Analyses on characters of surface radiation and energy at oasis-desert transition zone in Dunhuang. - Plateau Meteorology 24: 556-562.

[21] Wang, H., Hu, Z., Ma, W., Li, D. (2008): The seasonal variation of microclimate characteristics and energy transfer in the surf ace layer over Dingxin Gobi. - Chinese Journal of Atmospheric Sciences 32: 1458-1470.

[22] Wang, S., Ma, Q., Ding, H., Liang, H. (2018): Detection of urban expansion and land surface temperature change using multi-temporal landsat images. - Resources, Conservation and Recycling 128: 526-534. 
[23] Yang, X., Zhang, Q., Wang, R., Ma, P., Yang, Q., Liu, H. (2004): Experimental study on surface energy balance over Loess Plateau of middle part Gansu in summer. - Plateau Meteorology 23: 828-834.

[24] Yaşar Korkanç, S. (2018): Effects of the land use/cover on the surface runoff and soil loss in the Niğde-Akkaya Dam Watershed, Turkey. - Catena 163: 233-243.

[25] Zhang, J., Ge, J. P., Guo, Q. X. (2001): Effects of climatic factors on NDVI changes of main vegetation types in Eastern China. - Acta Ecologica Sinica 21(4): 522-527.

[26] Zhang, Q., Cao, X. (2003): The influence of synoptic conditions on the averaged surface heat and radiation budget energy over desert or Gobi. - Chinese Journal of Atmospheric Sciences 27: 245-254.

[27] Zhang, K., Wang, R., Zhang, Q., Si, J., Yang, Q., Liu, H., Wang, H. (2007): Characteristics of surface radiation and energy balance as well microclimate within oasisdesert ecotone of Zhangye on typical clear days in summer. - Journal of Desert Research 27: 1055-1061.

[28] Zhang, B. Q., Wu, P. T., Zhao, X. N., Wang, Y. B., Gao, X. D. (2013): Changes in vegetation condition in areas with different gradients (1980-2010) on the loess Plateau, China. Environ Earth Sci 68: 2427-2438.

[29] Zhang, Y. L., Gao, J. G., Liu, L. S., Wang, Z. F., Ding, M. J., Yang, X. C. (2013): NDVIbased vegetation changes and their responses to climate change from 1982 to 2011: a case study in the Koshi River Basin in the middle Himalayas. - Glob Planet Chang 108: 139148. 